\title{
Fuzzy Postprocessing to Advance the Quality of Continental Seasonal Hydrological Forecasts for River Basin Management $\mathscr{O}$
}

\author{
Hector Macian-Sorribes, ${ }^{\mathrm{a}}$ Illas Pechlivanidis, ${ }^{\mathrm{b}}$ Louise Crochemore, ${ }^{\mathrm{b}}$ AND \\ MANUEl PUlido-VelazQuez ${ }^{\mathrm{a}}$ \\ ${ }^{a}$ Research Institute of Water and Environmental Engineering (IIAMA), Universitat Politècnica de València, Valencia, Spain; \\ ${ }^{\mathrm{b}}$ Hydrology Research Unit, Swedish Meteorological and Hydrological Institute, Norrköping, Sweden
}

(Manuscript received 18 November 2019, in final form 12 August 2020)

\begin{abstract}
Streamflow forecasting services driven by seasonal meteorological forecasts from dynamic prediction systems deliver valuable information for decision-making in the water sector. Moving beyond the traditional river basin boundaries, large-scale hydrological models enable a coordinated, efficient, and harmonized anticipation and management of water-related risks (droughts, floods). However, the use of forecasts from such models at the river basin scale remains a challenge, depending on how the model reproduces the hydrological features of each particular river basin. Consequently, postprocessing of forecasts is a crucial step to ensure usefulness at the river basin scale. In this paper we present a methodology to postprocess seasonal streamflow forecasts from large-scale hydrological models and advance their quality for local applications. It consists of fuzzy logic systems that bias-adjust seasonal forecasts from a large-scale hydrological model by comparing its modeled streamflows with local observations. The methodology is demonstrated using forecasts from the pan-European hydrological model E-HYPE at the Jucar River basin (Spain). Fuzzy postprocessed forecasts are compared to postprocessed forecasts derived from a quantile mapping approach as a benchmark. Fuzzy postprocessing was able to provide skillful streamflow forecasts for the Jucar River basin, keeping most of the skill of raw E-HYPE forecasts and also outperforming quantile-mapping-based forecasts. The proposed methodology offers an efficient one-to-one mapping between large-scale modeled streamflows and basin-scale observations preserving its temporal dependence structure and can adapt its input set to increase the skill of postprocessed forecasts.
\end{abstract}

KEYWORDS: Seasonal forecasting; Hydrologic models; Mesoscale models

\section{Introduction}

Predicting the hydrological response in a river basin over the coming seasons can be of significant added value for water resources management (Contreras et al. 2020; Lavers et al. 2020). Recent investigations have demonstrated the benefits from the use of seasonal streamflow forecasting services at large (i.e., continental) and regional scales (Crochemore et al. 2020; Y. Li et al. 2017; Pechlivanidis et al. 2020; Wanders et al. 2019). Statistical streamflow forecasting approaches commonly relying on stochastic modeling techniques (Foster et al. 2018; Pianosi and Soncini-Sessa 2009; Pina et al. 2017) have recently been complemented by forecasting services driven by seasonal dynamic prediction systems (Arnal et al. 2018; Johnson et al. 2019; MacLachlan et al. 2015). A number of applications of seasonal forecast information for decisionmaking can be found in water-related sectors, i.e., urban water supply (Guo et al. 2018), hydropower (Giuliani et al. 2020; Raso and Malaterre 2017; Sreekanth et al. 2012; Wu et al. 2016), agriculture and droughts (Brown and Rogers 2006; Y. Li et al. 2017; Wetterhall et al. 2015), flood protection (Arnal et al. 2016; Ficchì et al. 2016; Neumann et al. 2018b),

Supplemental information related to this paper is available at the Journals Online website: https://doi.org/10.1175/JHM-D-190266.s1.

Corresponding author: Hector Macian-Sorribes, hecmasor@ upv.es and transport (Meißner et al. 2017). However, the potential of seasonal forecasts is not linearly dependent on the skill of a given forecasting system, accounting also how this skill is transformed into improved operational decisions by stakeholders (Crochemore et al. 2016; Y. Li et al. 2017; Neumann et al. 2018a).

Traditionally, hydrological modeling and forecasting is performed at the river basin (regional) scale, which allows an adequate representation of the hydrological cycle. Large-scale (continental and/or global) modeling is usually set to take into account human impacts (i.e., irrigation, reservoir operation) and provide a comprehensive understanding to enable a coordinated management of water and water-induced risks (Nazemi and Wheater 2015; Pechlivanidis and Arheimer 2015). Continental models have proven as powerful tools to address water-related risks (droughts, floods) in a coherent and harmonized way (Ramos et al. 2007), and evaluate information at gauged and ungauged locations (Donnelly et al. 2016).

Despite recent scientific advantages in process understanding, continental models are challenged by uneven performance across the modeled territory caused by factors such as spatial heterogeneities and lack of reliable data (Abbaspour et al. 2015; Andersson et al. 2015; Beck et al. 2016; Crochemore et al. 2020). Furthermore, the calibration of continental models is challenging, requiring a large sample of observations and also regionalization approaches to adequately estimate the model parameters (Hundecha et al. 2016; Samaniego et al. 2010). Considering the aforementioned challenges, the applicability of continental models at the river basin scale can be challenging. 
To adjust the hydrological information to local conditions, postprocessing is required to bridge the gap between continentalscale models and river-basin scale applications (Maraun et al. 2010; Teutschbein et al. 2011; Yang et al. 2010). These postprocessors are usually statistical models that derive the joint probability distribution of continental-scale forecasts and the corresponding regional observations and then apply it to derive hydrological forecasts that preserve the statistical properties of the observations. However, these methods assume stationary conditions, which challenges the prediction of unprecedented extreme values when tailored to a particular location and forecasting system (W. Li et al. 2017). Furthermore, the parameters of a statistical postprocessing function tailored to a particular meteorological forecast product, area and climate period are not directly applicable to other ones.

As alternative to statistical processes, heuristic approaches such as artificial neural networks (ANN), Bayesian networks (BN), fuzzy logic (FL), and decision trees (DT) have been proven to efficiently model mathematical relationships between variables (Dobson et al. 2019; Rani and Moreira 2010). Fuzzy logic has the ability to express uncertainty and vagueness in a mathematical way, using fuzzy sets, and efficiently operate with them (Sen 2010). It is also able to handle mathematical relationships that are complex and difficult to elicit and encode. Fuzzy logic has been proven as an efficient way to infer streamflows depending on variables such as precipitation, soil moisture, and evapotranspiration (Sen 2010; Turan and Yurdusev 2016), and to derive reservoir operating rules depending on past and current hydrological and reservoir information such as inflows and current storage levels (MacianSorribes and Pulido-Velazquez 2017; Russell and Campbell 1996; Shrestha et al. 1996).

In this paper, we explore fuzzy logic as an alternative postprocessing method to adjust seasonal streamflow forecasts from continental-scale models to the regional scale, enhancing the usability of existing continental forecasting services. We pose the following scientific questions: 1) What is the seasonal streamflow forecasting skill from existing continental services? 2) How can postprocessing methods influence the usability of the seasonal forecasts at the regional scale? 3) Is fuzzy logic a suitable postprocessing alternative compared to "common" methods? We answer these questions through an application of the proposed methodology in the Jucar River basin (eastern Spain).

The paper is organized as follows. Section 2 presents the case study and available data, while section 3 introduces the proposed postprocessing method. Section 4 presents the results from the comparison between the different forecasting systems. Finally, section 5 discusses the results and section 6 states the conclusions.

\section{Case study and data}

\section{a. The Jucar River basin}

The Jucar River is one of the most important watercourses in eastern Spain, with a length of $497 \mathrm{~km}$ between the Iberian Mountains and the Mediterranean Sea. Its basin covers an area of $22260 \mathrm{~km}^{2}$ mainly located in the regions of Castilla-La Mancha and Comunitat Valenciana (Fig. 1), with the Cabriel, Magro, and Albaida Rivers being its main tributaries. Its precipitation pattern is Mediterranean (high rainfall in autumn and very little precipitation during summer), ranging between 309 and $717 \mathrm{~mm} \mathrm{yr}^{-1}$ (with an average of $473 \mathrm{~mm} \mathrm{yr}^{-1}$ ). Its average hydrological streamflow is equal to $1548 \mathrm{Mm}^{3} \mathrm{yr}^{-1}$ (CHJ 2015). Around $70 \%$ of streamflow comes from groundwater contribution as baseflow. The main reservoirs in the basin are Alarcon (1088 $\mathrm{Mm}^{3}$ useful storage), Contreras $\left(429 \mathrm{Mm}^{3}\right)$, and Tous $\left(369 \mathrm{Mm}^{3}\right)$. The smaller Forata $\left(36 \mathrm{Mm}^{3}\right)$ and Bellus $\left(68 \mathrm{Mm}^{3}\right)$ reservoirs are placed in the Magro and Albaida Rivers, respectively. The annual mean consumptive demand is equal to $1505 \mathrm{Mm}^{3}$ (CHJ 2015) divided into urban (9\%), agricultural (89\%), and industrial (2\%). The main cities are Valencia, Albacete, Cuenca, and Sagunto. The most important irrigated areas are placed in the lower basin (downstream Tous reservoir) and in the Mancha Oriental area (Albacete province).

The Jucar River basin is divided into seven subbasins. Alarcon and Contreras subbasins have similar hydrological features as the Magro and Albaida subbasins. Skillful hydrological forecasts are particularly important in these headwater subbasins during the refill season (from October to April) to anticipate the state of the main Jucar reservoirs for the upcoming irrigation season (from May to September). The Mancha and Middle subbasins refer to the middle Jucar and Cabriel watercourses, from Alarcon and Contreras to Tous. The Mancha subbasin mainly corresponds to the drainage of the Mancha Oriental aquifer, the largest groundwater body in the basin, which holds the major groundwater-irrigated area. Skillful streamflow forecasts in these subbasins are important for the existing hydropower plants and minimum environmental flows during the whole year and, during the irrigation season, for balancing Alarcon and Contreras releases. The lower subbasin corresponds to the Jucar River floodplain, which holds the vast majority of the surface water demands. Hydrological forecasts for this area are crucial during the irrigation season, since low streamflow needs to be compensated by reservoir releases.

Streamflow data as well as inflows, storages and releases from reservoirs are publicly available from the Automatic System for Hydrological Information of the Jucar River basin [Sistema Automático de Información Hidrológica (SAIH), http://saih.chj.es/chj/saih/glayer?t=a], and from the Annual Report on Gauging Stations from the Ministry of Ecological Transition of Spain (CEDEX 2016). Naturalized (impaired) streamflow observations of the Jucar River subbasins in Fig. 1, restituted to natural regime (using streamflow observations, water Abstractions, and return flows), are obtained from the Jucar River Basin Authority [Confederación Hidrográfica del Júcar $(\mathrm{CHJ})]$. These are key inputs to the water resource system models used by $\mathrm{CHJ}$ in planning and operation $(\mathrm{CHJ}$ 2015), and thus are the key hydrological variables to predict.

\section{b. Pan-European seasonal hydrological forecasts}

We extract seasonal streamflow forecasts from the panEuropean service run by the Swedish Meteorological and Hydrological Institute (SMHI). The service is based on the E-HYPE hydrological model, which is the pan-European setup of the Hydrological Predictions for the Environment (HYPE) distributed hydrological model (Lindström et al. 2010) running at daily time step (Donnelly et al. 2016). E-HYPE covers an area of 8.8 million $\mathrm{km}^{2}$ divided into about 35400 catchments with a median size of $214 \mathrm{~km}^{2}$. Its calibration and evaluation 


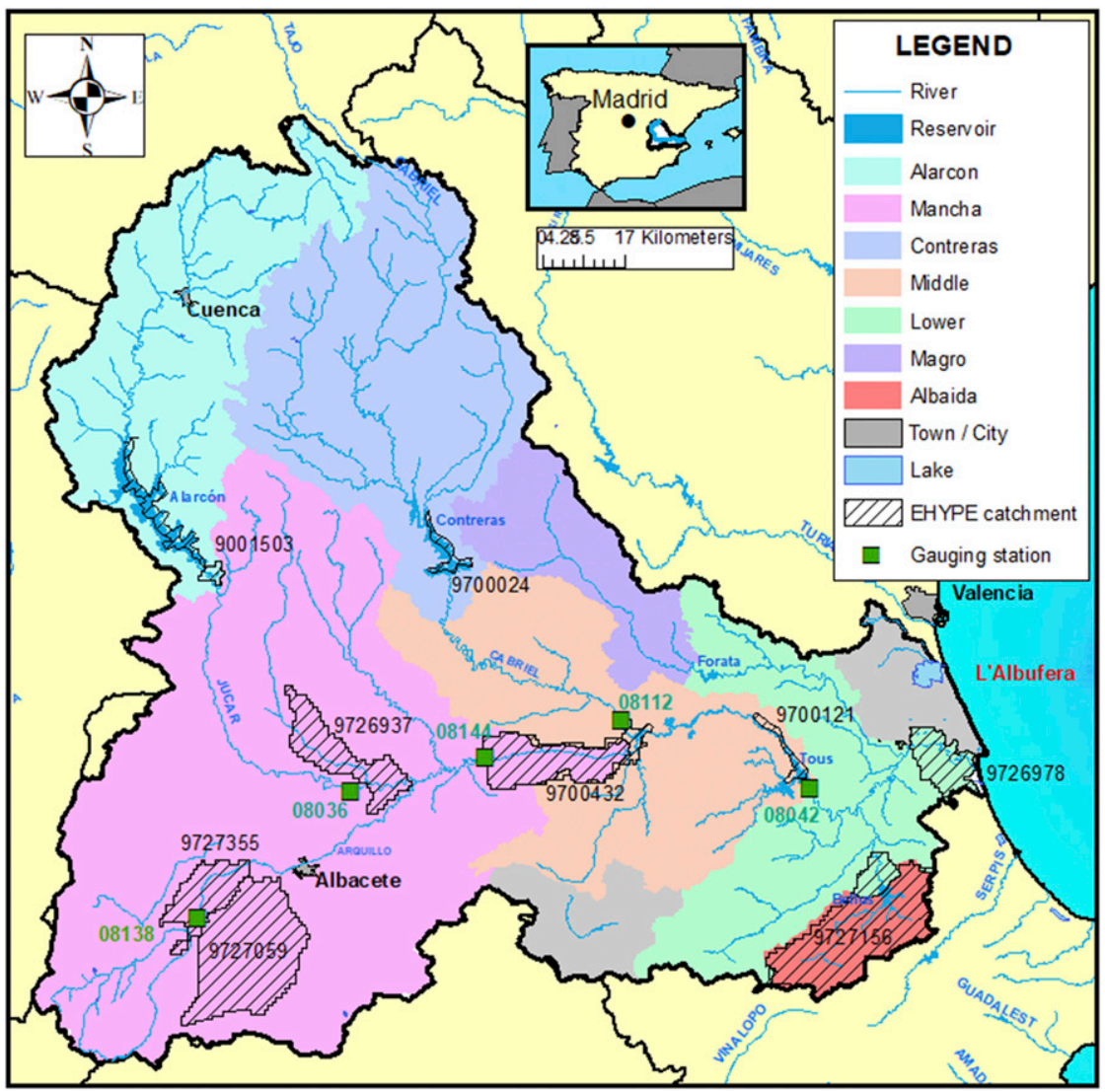

FIG. 1. Jucar River basin hydrological map (colored areas), gauging stations (green squares), and relevant E-HYPE catchments (dashed).

included hydrological streamflow observations at 115 and 538 stations, respectively, applying a stepwise regionalization approach for parameter estimation (Hundecha et al. 2016). In this paper we use the term "catchment" when referring to the hydrological divisions used by E-HYPE, and "subbasin" when referring to the hydrological divisions of the Jucar River basin.

Seasonal streamflow forecasts are available from the E-HYPE model driven by meteorological (precipitation and temperature) forecasts from the European Centre of Medium-Range Weather Forecasts (ECMWF) System 4. These forcing meteorological forecasts were bias-adjusted prior to this study by means of the distribution-based scaling method (Yang et al. 2010), using as reference the statistical properties and probability distributions from the HydroGFD dataset (a global reanalysis dataset conditioned to observations; Berg et al. 2018). The hindcast period is from 1 January 1981 to 31 December 2010, with 15 daily-scale ensemble members issued at the first of each month for a forecast horizon of 7 months. E-HYPE modeled streamflows are also available for the same period representing the "perfect forecasts."

\section{Method}

\section{a. Proposed approach}

The methodology developed to postprocess continentalscale seasonal hydrological forecasts is based on fuzzy logic systems that map streamflow forecasts from a continental model (inputs) to forecasts at user-specified locations of the target river basin (outputs) (Fig. 2). For each location, catchments from the continental model are chosen as inputs to the postprocess method by performing a suitability analysis comparing their modeled streamflows (hydrological model forced with historical meteorological inputs) against observations at the given locations. A single fuzzy logic system is developed for each location, using modeled streamflows and naturalized observations. The method respects the temporal dependence structure of the time series during the mapping process, since each single modeled streamflow is mapped to the naturalized observation found at the same time stage. These fuzzy logic systems are then used to transform seasonal hydrological forecasts from the continental model into forecasts at the relevant locations applying a fuzzy inference process. The analysis period is the same as the hindcast period (1981-2010). Although the proposed postprocessing method can be applied to any time step, here we use monthly averages of daily streamflows.

\section{b. Fuzzy logic systems building and inference}

The process of using fuzzy logic systems to postprocess continental hydrological forecasts (Fig. 3) can be divided into fuzzy logic system building and fuzzy inference. Building a 


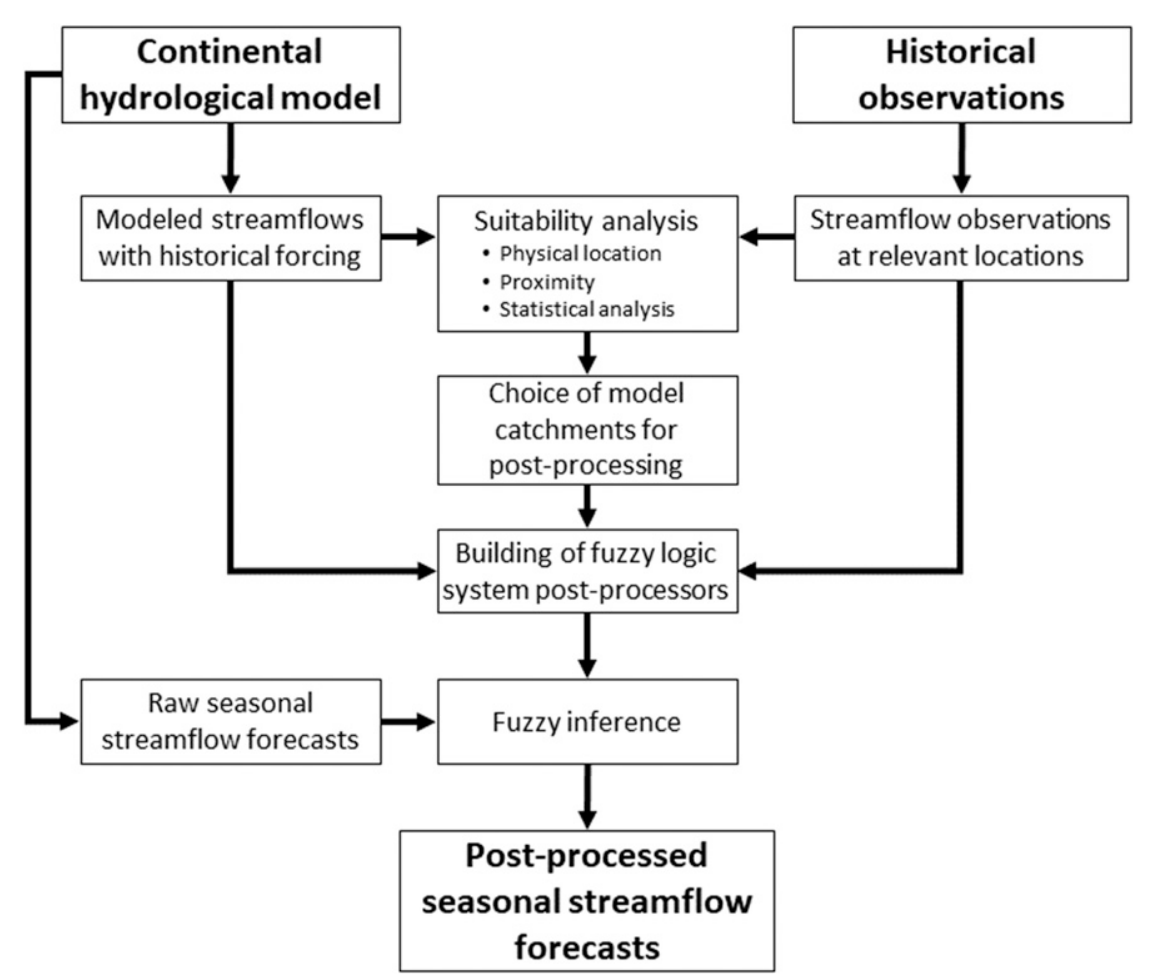

FIG. 2. Proposed methodology for postprocessing continental streamflow forecasts.

fuzzy logic system requires: 1) characterization of the input variables (modeled streamflows from the continental model) and quantification using fuzzy numbers; 2) setting up fuzzy rules by combining inputs; 3 ) selection of outputs; 4) training of the predefined fuzzy logic system; and 5) evaluation of the trained system. After building, the operation of a fuzzy logic system (known as fuzzy inference) requires: 1) previous operations on raw inputs if necessary; 2) fuzzification of inputs by comparing their values with the fuzzy numbers associated with input variables; 3 ) rule triggering to determine the degree of fulfillment of each fuzzy rule according to fuzzified inputs; 4) output composition from the outputs of the triggered rules; and
5) final operations to refine the output if necessary. Fuzzy logic systems of Sugeno type of order 0 were used for postprocessing hydrological forecasts of the Jucar River basin. A comprehensive description of these stages is provided in the first part of the online supplemental material.

\section{c. Historical suitability analysis}

The historical suitability analysis compares modeled streamflows of E-HYPE with observations at selected locations of the Jucar River basin (Table 1) to estimate how well E-HYPE reproduces its hydrological behavior and to choose the catchments to be used as input variables by the postprocessing fuzzy logic

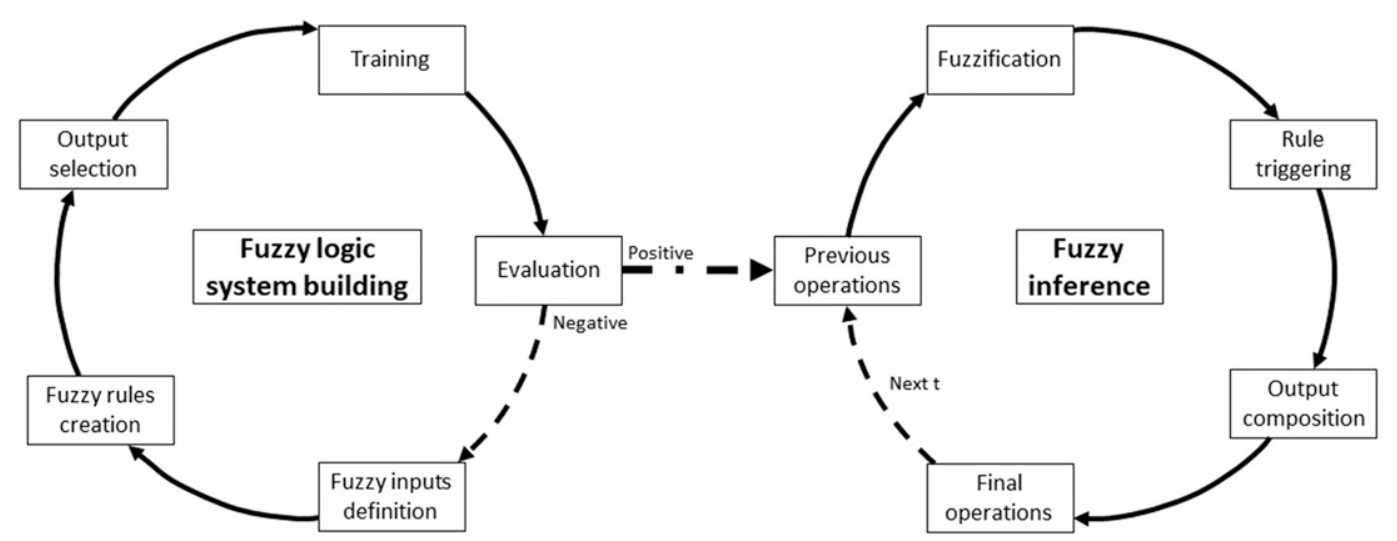

FIG. 3. Fuzzy logic system building and inference procedure. 
TABLE 1. Gauging stations and E-HYPE catchments used in the historical suitability analysis.

\begin{tabular}{lccc}
\hline \hline \multicolumn{1}{c}{$\begin{array}{c}\text { Location } \\
\text { name }\end{array}$} & $\begin{array}{c}\text { Jucar } \\
\text { gauge ID }\end{array}$ & $\begin{array}{c}\text { Associated } \\
\text { E-HYPE } \\
\text { catchment }\end{array}$ & $\begin{array}{c}\text { Location drainage } \\
\text { area }\left(\mathrm{km}^{2}\right)\end{array}$ \\
\hline Alarcon reservoir & E8001 & 9001503 & 2937 \\
Contreras reservoir & E8009 & 9700024 & 3266 \\
Balazote & 08138 & 9727355 & 792 \\
Estacadilla & - & 9727059 & 503.32 \\
Los Frailes & 08036 & 9726937 & 5403 \\
Cofrentes & 08112 & 9700432 & 4694 \\
Tous reservoir & 08042 & 9700121 & 17821 \\
Bellus reservoir & E8032 & 9727156 & 493 \\
Outlet & C8154 & 9726978 & 21561 \\
\hline
\end{tabular}

systems. A number of E-HYPE catchments (shown in Fig. 1) were identified as candidate inputs considering their physical location (covering the whole Jucar River basin) and their proximity to reservoirs and gauging stations (which allows comparing their streamflows with observations and naturalized observations). The best candidates are the catchments whose outlets are located at reservoirs, gauging stations, or Jucar River subbasins' outlets. To choose the inputs for each fuzzy logic system among the candidates, their modeled streamflows were compared with the naturalized observations of each Jucar River subbasin. The comparison was done through the modified Kling-Gupta efficiency index (KGEM; Kling et al. 2012), and its three decomposed terms ( $r, \beta$, and $\gamma)$. Its formulation is provided in the second part of the online supplemental material.

\section{d. Fuzzy postprocessing of pan-European forecasts}

In case of positive KGEM in at least one candidate, input catchments were chosen based on the KGEM. In case of negative KGEM values in all candidates, input catchments were selected based on the correlation coefficient $r$, since fuzzy logic systems were found to be more skilled in correcting the variability in the streamflow signal than in adjusting the temporal dynamics (i.e., autocorrelation coefficient). The decision on the number of inputs depends on the KGEM and $r$ values. In general, two inputs were chosen if all KGEM values were positive or all $r$ coefficients were higher than 0.5 , while three inputs were chosen otherwise. We considered that the increase in complexity associated with adding a fourth input in subbasins with already three inputs would not be compensated by the value of adding more information. For each input, linguistic descriptors were attached: five linguistic descriptors were chosen (very low, low, medium, high, and very high) in case of two inputs; and three linguistic descriptors (low, medium, and high) in case of three inputs. This choice balances the complexity of the fuzzy logic system with the number of inputs, avoiding an excessive number of rules in case of three inputs and taking advantage of the relatively close relationship between inputs and outputs in the case of two inputs.

Once input variables were chosen, fuzzy logic systems for each subbasin were developed applying the process described in section 3 b. Triangular fuzzy numbers linked to linguistic
TABLE 2. Jucar River subbasins and corresponding E-HYPE catchments used in quantile mapping.

\begin{tabular}{lcc}
\hline \hline Subbasin & $\begin{array}{c}\text { Corresponding } \\
\text { E-HYPE catchment }\end{array}$ & $\begin{array}{c}\text { Subbasin } \\
\text { drainage } \\
\text { area }\left(\mathrm{km}^{2}\right)\end{array}$ \\
\hline Alarcon & 9001503 & 2937 \\
Mancha & 9700432 & 7979 \\
Contreras & 9700024 & 3266 \\
Middle & 9700121 & 2962 \\
Lower & 9726978 & 2274 \\
Magro & 9700121 & 1011 \\
Albaida & 9727158 & 493 \\
\hline
\end{tabular}

descriptors were built following the next stages: 1) the modal value of each fuzzy number (upper vertex) was chosen according to the statistical properties of the modeled streamflows (minimum, first quartile, median, third quartile, and maximum in the case of two inputs; and minimum, median, and maximum in the case of three inputs); and 2) the lower vertices of each fuzzy number were chosen to make them coincide with the modal values of the neighboring fuzzy numbers (e.g., the lower right vertex of the fuzzy number linked to "very low" in a fuzzy logic system of two inputs is equal to the modal value of the fuzzy number associated with "low"). This way of building the fuzzy numbers allows an equitable division of the space of each variable in terms of its probability distribution and an adequate level of overlap between fuzzy numbers. After the input definition, fuzzy rules were created considering all possible combinations between linguistic descriptors. Consequently, fuzzy logic systems with two inputs had 25 rules $(5 \times 5)$ and fuzzy logic systems with three inputs had 27 rules $(3 \times 3 \times 3)$.

Each fuzzy logic system was given one output: the naturalized streamflow of the corresponding subbasin. For each fuzzy rule, the output is defined as a nonfuzzy number according to the Sugeno type of order 0 formulation. All systems were trained against naturalized observations for the 1981-2005 period and evaluated against naturalized observations for the 2006-10 period. The training process was automatic, using a solver to adjust the values of the fuzzy rules' outputs seeking the maximization of the KGEM index.

\section{e. Benchmarking forecasts and skill assessment}

As benchmark we consider a postprocessing method based on quantile mapping to quantify the added value of the fuzzy postprocessing. The quantile mapping procedure maps the cumulative probability distribution of raw E-HYPE forecasts with the cumulative probability distribution of the naturalized observations of the corresponding subbasin (Table 2). In the Jucar River basin, four subbasins share their outlet with their corresponding E-HYPE catchment (Alarcon, Mancha, Middle, and Lower); and there are two subbasins whose outlet is close to and along the same river as the outlet of their corresponding E-HYPE catchment (Contreras and Albaida). For the Magro subbasin, its particular configuration (two rivers that converge at its outlet) prevents associating it to a single E-HYPE catchment. Considering this and the existence of neighboring catchments with similar hydrological 
patterns in the Jucar River, the corresponding catchment of the Magro is placed on the Jucar River.

The performance of the fuzzy logic postprocessing was evaluated in two steps: 1) contrasting the skill of the fuzzy postprocessed forecasts with the one achieved by the raw forecasts and 2) contrasting the skill of the fuzzy postprocessed forecasts with the skill obtained by quantile mapping. The skill of each forecasting system was measured using the continuous rank probability score (CRPS) and the continuous rank probability skill score (CRPSS) (Hersbach 2000; Matheson and Winkler 1976). Reference forecasts for computing meteorological skills were observations form HydroGFD. Reference forecasts for computing raw E-HYPE skills were E-HYPE modeled streamflows. Reference forecasts for postprocessed E-HYPE skills were the results of applying the postprocessing fuzzy logic systems to the E-HYPE modeled streamflows. The added value of the proposed methodology with respect to quantile mapping was estimated calculating the CRPSS of fuzzy postprocessed E-HYPE forecasts with quantile mapping as reference forecasts. The formulation of CRPS and CRPSS is provided in the second part of the online supplemental material.

\section{Results}

Here, we first assess the E-HYPE model performance over the historical period in order to determine the need (or not) of postprocessing. Afterward, we assess the meteorological forecasting skill, followed by a skill assessment of the E-HYPE hydrological forecasts. Then, we present the building, training and evaluation of the fuzzy logic systems for postprocessing. Finally, we assess the skill of the postprocessed E-HYPE hydrological forecasts and compare the performance of fuzzy postprocessing with postprocessed forecasts based on quantile mapping.

\section{a. Historical suitability assessment}

E-HYPE modeled streamflows and observations, as well as the KGEM and its decomposed terms for the analysis period, are shown in Fig. 4. Results show large differences between modeled streamflows and observations in most locations, which was to a certain extent expected due to the strong human impact (i.e., streamflow regulation) in the region, which further challenges the E-HYPE model setup and parameter identification. Moreover, the Jucar River is impacted by excessive groundwater Abstraction in the Mancha region (Mancha Oriental aquifer), causing streamflow depletion (through stream-aquifer interaction) challenging to be reproduced by E-HYPE. Moreover, the continental E-HYPE model is setup using open global datasets which are usually prone to larger uncertainty/error than local/regional datasets (Kauffeldt et al. 2013).

The influence of regulation is clearly shown by the decrease of the model performance along the river (from upstream to downstream locations). Results at catchments which are not subject to significant upstream modifications (Alarcon, Contreras and Bellus reservoirs) show adequate values for correlation coefficient, particularly in the Alarcon reservoir. Consequently, raw E-HYPE streamflow outputs can be directly used at the Alarcon subbasin (whose outlet corresponds to the Alarcon reservoir), and may be employed at Contreras and Bellus subbasins (whose outlets correspond to the reservoirs of the same name) taking into account that they can introduce large biases (in particular for high streamflows). Moreover, results show a poor performance between E-HYPE and observations for the Arquillo River (gauge 08138), with no surface regulation but affected by groundwater overdraft. Furthermore, understanding and representation of impacts caused by the hydropower reservoirs located between the Jucar and Cabriel confluence and Tous reservoir is also challenging, as shown by the decrease in the KGEM values between both locations. However, the largest KGEM decrease is caused by the surface-irrigated agricultural areas downstream of Tous, which are subject to a complex regulation scheme that poses a major challenge even to detailed (locally setup) water resource management models.

\section{b. Skill of forcing meteorological forecasts}

Here, we assess the forecasting skill (in terms of CRPSS) for all lead months (0-6) and seasons. Figure 5 depicts the percentage of forecasts with skill (positive CRPSS) for the analysis period. Percentages above $50 \%$ (greenish areas) represent skillful forecasts, since they outperform the reference forecasts during more than $50 \%$ of the analysis period, while percentages below $50 \%$ (reddish areas) represent unskillful forecasts for similar explanations as before. Overall, precipitation forecasts do not show skill beyond lead month 0 , which is also in line with previous findings (see Arnal et al. 2018). The only exception is found in spring, during which precipitation forecasts for lead month 1 show skill for the Mancha and Lower subbasins. Precipitation forecasts initialized in the summer months show the highest skill in most of the Jucar River basin (upper and middle sections). However, precipitation volumes are the lowest in the summer months, which means that the model has skill in foreseeing this feature of the Mediterranean climate in the Jucar River basin. Results for autumn are similar to those for summer, although lower skill is observed. Forecasts in winter achieve the highest skill for the upper basins of the Jucar, despite not presenting skillful forecasts for the rest of the basin. Forecasts in spring are skillful only in the lower part of the Jucar River basin.

\section{c. Benchmarking seasonal hydrological forecasts}

We next assess the E-HYPE based seasonal streamflow forecasting skill before postprocessing. We note that using modeled streamflows as reference, instead of naturalized observations, allows evaluation of the hydrological predictability without taking into account the E-HYPE model performance for the region. Figure 6 depicts the percentage of forecasts with skill for the analysis period similarly to Fig. 5.

It is generally observed that hydrological forecasts are overall more skillful than precipitation forecasts. Hydrological forecasts in spring show skill up to lead month 3 in parts of the Mancha and the lower Jucar ( 2 months above precipitation forecasts). However, the skill of the hydrological forecasts during this season in the headwaters of the Jucar River is positive until lead month 1 (lead month 2 in Alarcon) despite 

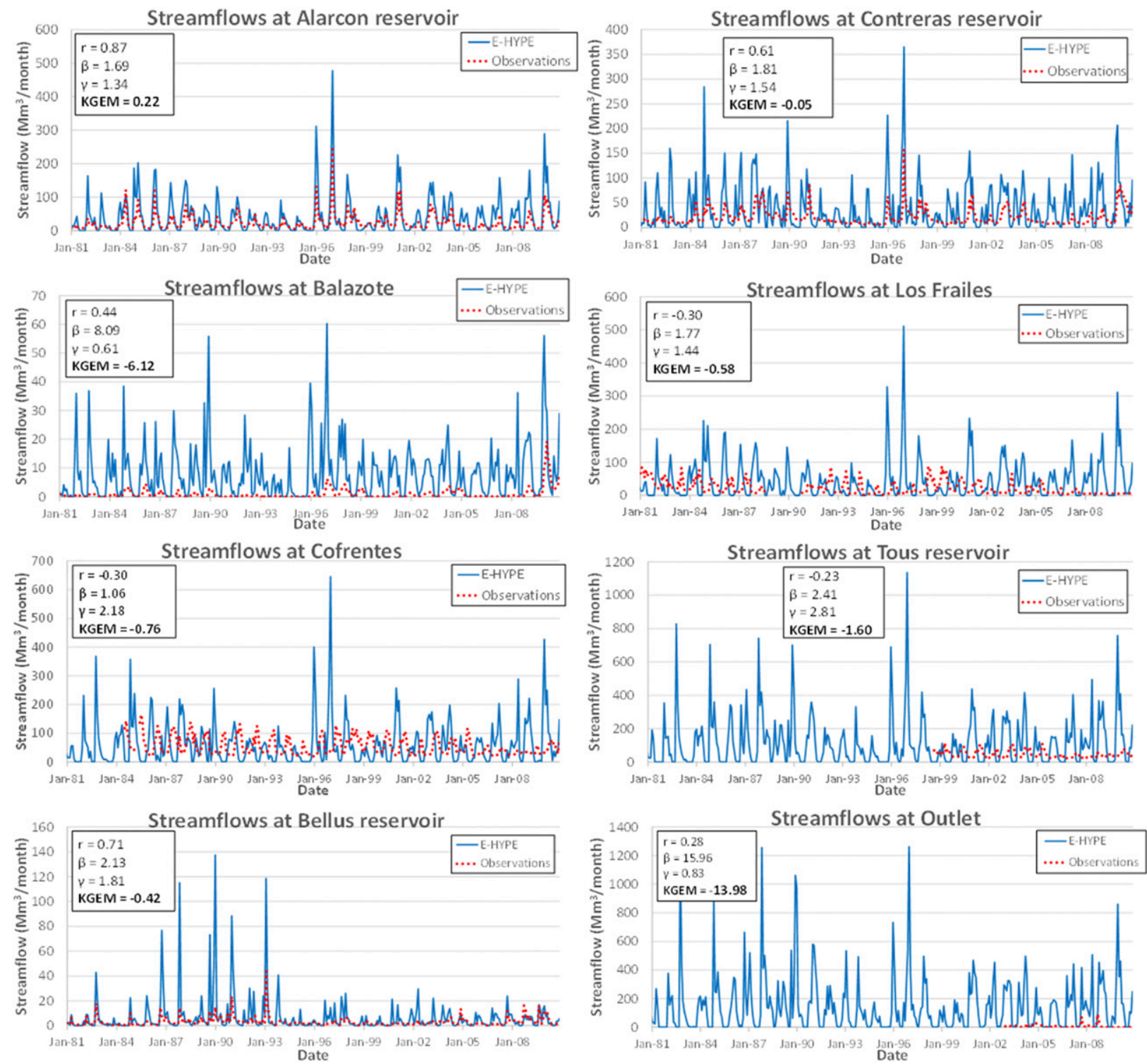

FIG. 4. Monthly time series of E-HYPE modeled streamflows and historical observations for candidate E-HYPE input catchments (see locations in Fig. 1 and Table 1) and associated KGEM indices and decomposed terms for the period 1981-2010.

the lack of skill in the precipitation forecasts. Winter forecasts show skill up to lead month 1 in almost all regions of the Jucar basin (particularly in the headwaters); however, summer and autumn show no skill beyond lead month 0 .

The observed increase in lead months with skill during winter and spring is due to the role played by groundwater bodies, which add a backup streamflow to rivers; streamaquifer interaction is easier to predict than meteorology if the initial conditions are properly assessed. The role of the initial hydrological conditions, in particular in the transition from a wet to a dry season and/or in a dry season, has been highlighted previously (Arnal et al. 2017; Shukla et al. 2013; Wood et al. 2016; Wood and Lettenmaier 2008). Although surface water bodies also contribute to the increase of predictability, their role in the Jucar River basin is considered secondary (see CHJ 2015). Groundwater contribution is observed in spring, during which the hydrological forecasts show skill up to lead month 1 (and even further ahead in some areas) despite the lack of skill in the precipitation forecasts.

\section{d. Fuzzy postprocessing of hydrological forecasts}

The historical suitability analysis highlighted the need to postprocess the E-HYPE seasonal forecasts and adjust them to the naturalized observations. Here we describe the process followed to build postprocessing fuzzy logic systems for the Jucar River basin. Table 3 shows the KGEM values comparing the E-HYPE modeled streamflows in the candidate catchments and the naturalized observations in the Jucar River 


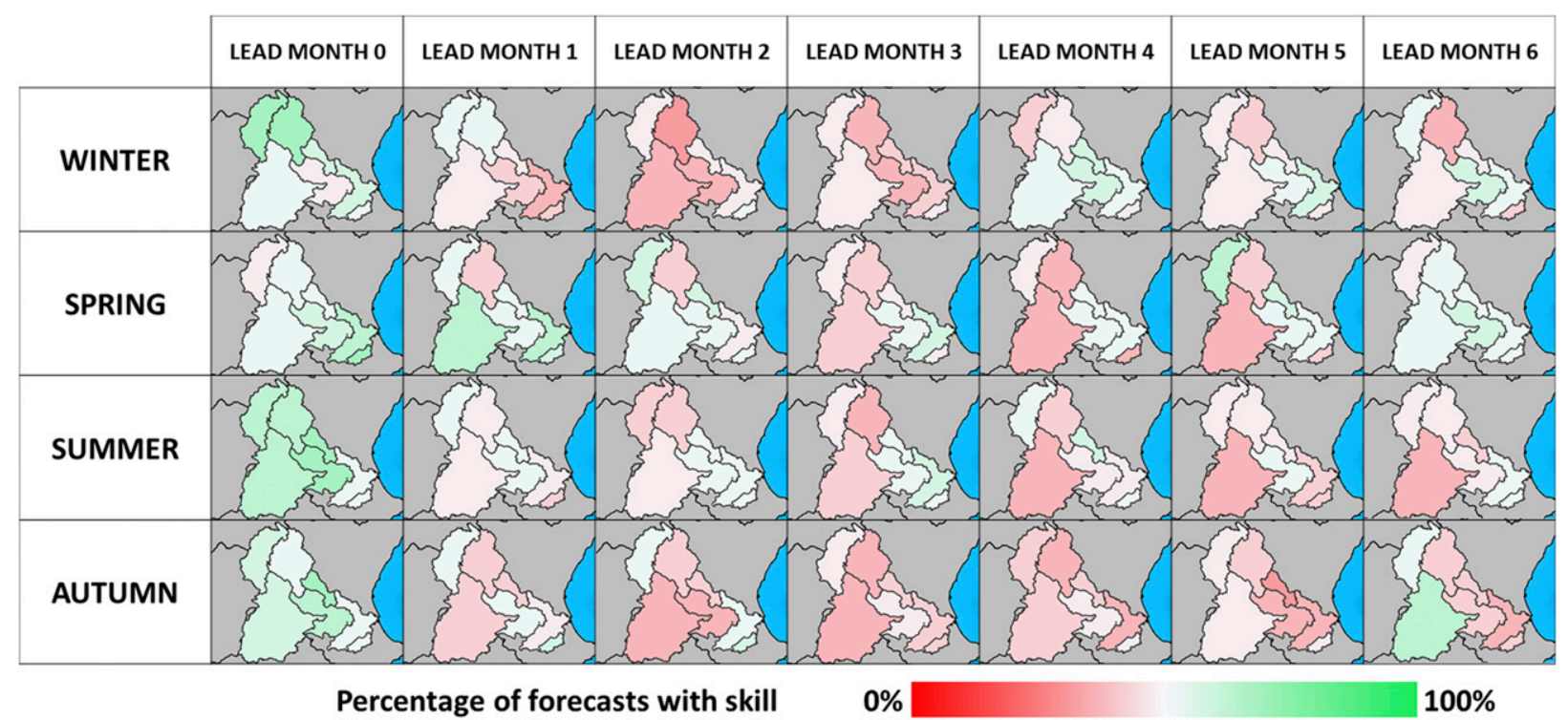

FIG. 5. Percentage of forecasts with skill of forcing precipitation forecasts (positive CRPSS) using HydroGFD as reference. Percentages above $50 \%$ mean skillful forecasts (green tones) while percentages below 50\% mean unskillful forecasts (red tones).

subbasins. Some catchments were discarded beforehand due to being physically far from the corresponding subbasin. Moreover, the Cofrentes catchment, in the center of the Jucar basin, was discarded due to the lack of forecasting skill. The inputs for the postprocessing fuzzy logic systems (shown in bold in Table 3) were chosen following the criteria indicated in section 3d. The only exception was the Contreras subbasin, in which the E-HYPE catchment of Contreras was chosen instead of Los Frailes (both showing similar $r$ values) due to the physical proximity. Alarcon and Contreras were given two inputs due to showing positive KGEM values in all the candidates (Alarcon) or $r$ higher than 0.5 (Contreras). In the case of the Albaida subbasin, two inputs were selected since the Bellus catchment showed an $r$ value of 0.71 . The inputs were characterized following the procedures described in section $3 \mathrm{~d}$, as the number of rules and outputs. Details on the fuzzy logic systems can be found in the third part of the online supplemental material.

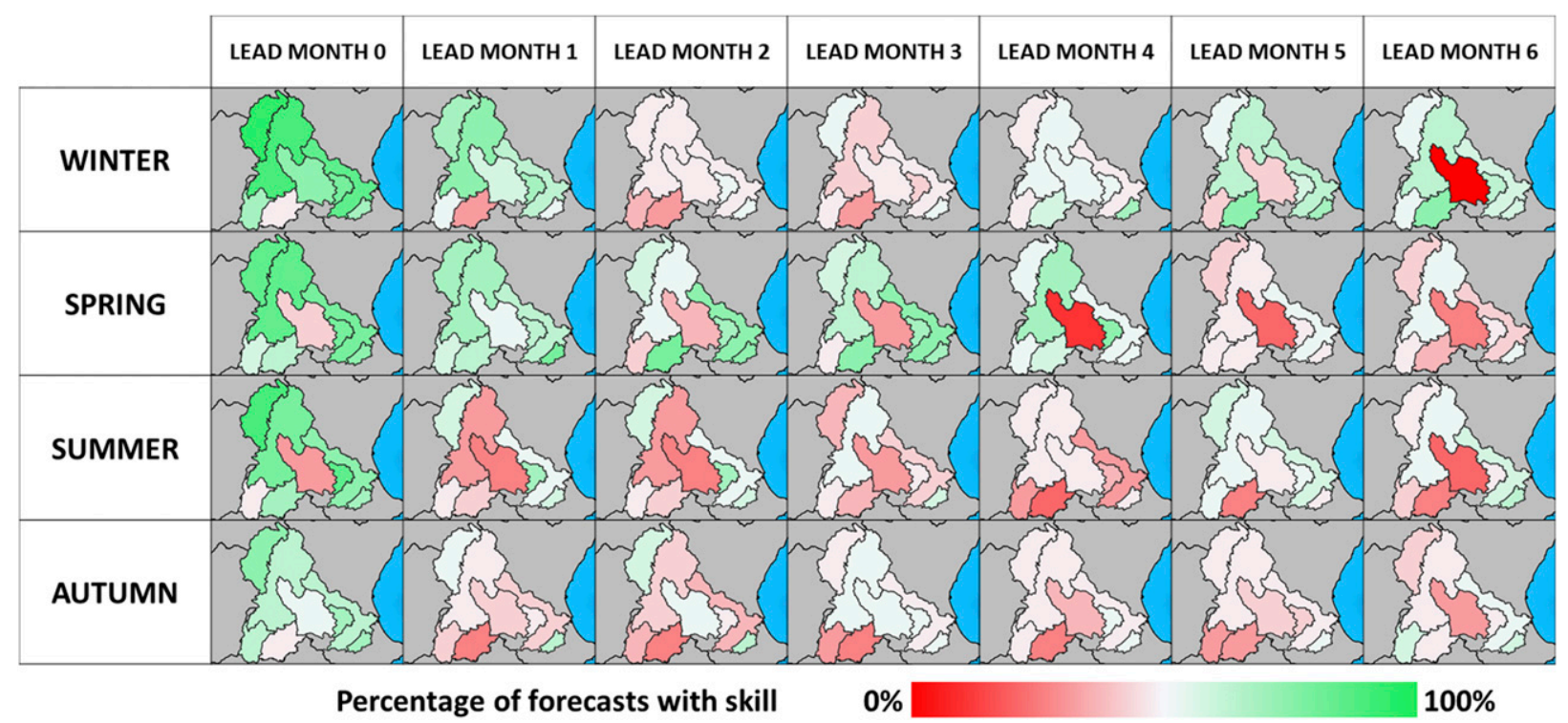

FIG. 6. Percentage of forecasts with skill of raw E-HYPE seasonal streamflow forecasts (positive CRPSS) using modeled streamflows as reference. Percentages above 50\% mean skillful forecasts (green tones) while percentages below $50 \%$ mean unskillful forecasts (red tones). 
TABLE 3. KGEM and $r$ terms (in brackets) for candidate input E-HYPE catchments and Jucar River subbasins. Postprocessing input catchments are shown in bold.

\begin{tabular}{|c|c|c|c|c|c|c|c|}
\hline \multirow[b]{2}{*}{ Location name (see Table 1) } & \multicolumn{7}{|c|}{ Jucar River subbasin naturalized observations } \\
\hline & Alarcon & Mancha & Contreras & Middle & Lower & Magro & Albaida \\
\hline Estacadilla & - & $-4.43(0.36)$ & - & - & - & - & - \\
\hline Bellus & - & - & - & - & $-0.52(0.68)$ & $-6.37(0.45)$ & $-0.42(0.71)$ \\
\hline Balazote & - & $-1.65(0.19)$ & - & $-0.41(0.33)$ & - & - & - \\
\hline Alarcon reservoir & $0.22(0.87)$ & $-2.14(0.05)$ & $-0.18(0.75)$ & $-1.51(0.08)$ & - & - & - \\
\hline Contreras reservoir & $0.29(0.66)$ & $-1.87(0.18)$ & $-0.05(0.61)$ & $-1.21(0.26)$ & - & $-46.89(0.53)$ & - \\
\hline Los Frailes & $0.14(0.86)$ & $-2.27(0.09)$ & $-0.27(0.74)$ & $-1.61(0.13)$ & $-0.49(0.18)$ & $-52.82(0.35)$ & - \\
\hline Tous reservoir & - & $-4.52(0.26)$ & - & $-6.08(0.36)$ & $-3.78(0.46)$ & $-142.65(0.58)$ & $-35.01(0.38)$ \\
\hline Outlet & - & - & - & $-8.25(0.42)$ & $-5.37(0.59)$ & $-183.10(0.65)$ & $-45.36(0.51)$ \\
\hline
\end{tabular}

Training of the fuzzy logic systems achieved a good performance in all subbasins, with KGEM being greater than 0.8 , expect from Mancha and Middle (Fig. 7). As mentioned in section $4 \mathrm{a}$, the challenging representation of groundwater mining in the Mancha Oriental aquifer could explain the poor performance for the Mancha and Middle subbasins. Alarcon shows the highest performance due to the good agreement shown between E-HYPE modeled streamflows and Jucar River naturalized observations. The other subbasins (expect from Mancha and Middle) show similar performance despite the number of inputs used, highlighting both the added value of fuzzy logic in forecast postprocessing and the adequacy of the fuzzy logic system setup. As expected, the KGEM values decrease in the evaluation period compared to the training period, for all subbasins, with the Alarcon subbasin showing again the highest performance during evaluation. The most distinct loss in the performance between training and evaluation period is found in the Albaida subbasin, due to a concentration of high naturalized observations after January 2008. However, its performance level was still found to be adequate, with the exception of those peaks.

\section{e. Postprocessed forecasts skill assessment}

We next evaluate the skill of E-HYPE seasonal streamflow forecasts after postprocessing. Figure 8 presents the percentage of postprocessed forecasts showing skill. Forecasts for the headwaters of the Jucar (Alarcon and Contreras) show skill until lead month 2 in spring and lead month 1 in the other seasons, which is the same period with skill as raw forecasts. It should be noted that the periods showing skill increase in Contreras after postprocessing, reaching lead month 2 in spring and lead month 1 in summer and autumn. Postprocessed forecasts for the middle Jucar show lower periods with skill than raw forecasts in winter (no skill) and spring (skill only in lead month 0 ), while in lead month 0 skill losses are observed in all seasons except autumn. An increase in the forecasting skill is observed in lead month 1 for the middle Jucar during summer and autumn; however, this is not significant to consider the forecasts skillful. A slight loss of skill is also found in the lower parts of the Jucar, with lower periods with skill during winter (skill only in lead month 0 ) and summer (no skill in lead month 0 and a slight skill in lead months 1 and 2), as well as lower skills for lead month 0 . A slight increase in skill is found in spring for lead month 1 and lead month 2 .
A complementary comparison is shown in Fig. 9, which presents the percentage of postprocessed forecasts with skill using raw forecasts as benchmark. This comparison provides a direct estimation of the impact of postprocessing on forecasting skill, although it is not able to measure if both, one, or no alternative offers reliable forecasts. Postprocessed forecasts show a loss in skill during winter, in particular for the upper and middle Jucar, while only slight changes are found during the rest of the seasons. However, this loss in skill does not imply, in the case of Alarcon and Contreras, a reduction in the periods for which skillful forecasts are provided, as found comparing Fig. 6 and Fig. 8. Forecasts in Contreras tend to show increased skills after postprocessing during spring, as well as Alarcon forecasts during summer. Postprocessed forecasts for the center of the Jucar show in general a slight increase, driven by the lack of skill of raw forecasts for the Cofrentes E-HYPE catchment. Furthermore, postprocessed forecasts for the lower Jucar show both increases and decreases of skill, although the lowest lead months (0 and 1) tend to show decreases.

\section{f. Added value of fuzzy postprocess in comparison to quantile mapping}

We next compare the results of the proposed postprocess method against quantile mapping computing the CRPSS using the latter as reference (Fig. 10). Results show a general prevalence of fuzzy postprocessed forecasts in the Jucar River basin, with some exceptions that mostly refer to its lowest part (Lower, Magro, and Albaida subbasins) and concentrate in winter and spring. In general, the comparison shows small differences between both methods. The improvements of fuzzy logic with respect to quantile mapping are found in all seasons but spring, and almost systematically in the Mancha, Middle, and Contreras subbasins. The results indicate that the methodology proposed is capable of providing skillful seasonal streamflow forecasts, outperforming quantile mapping in the Jucar River basin.

\section{Discussion}

\section{a. Continental forecasting services tailored to the regional conditions}

Continental climate services deal with regional needs at domains which are under strong hydroclimatic gradients and 

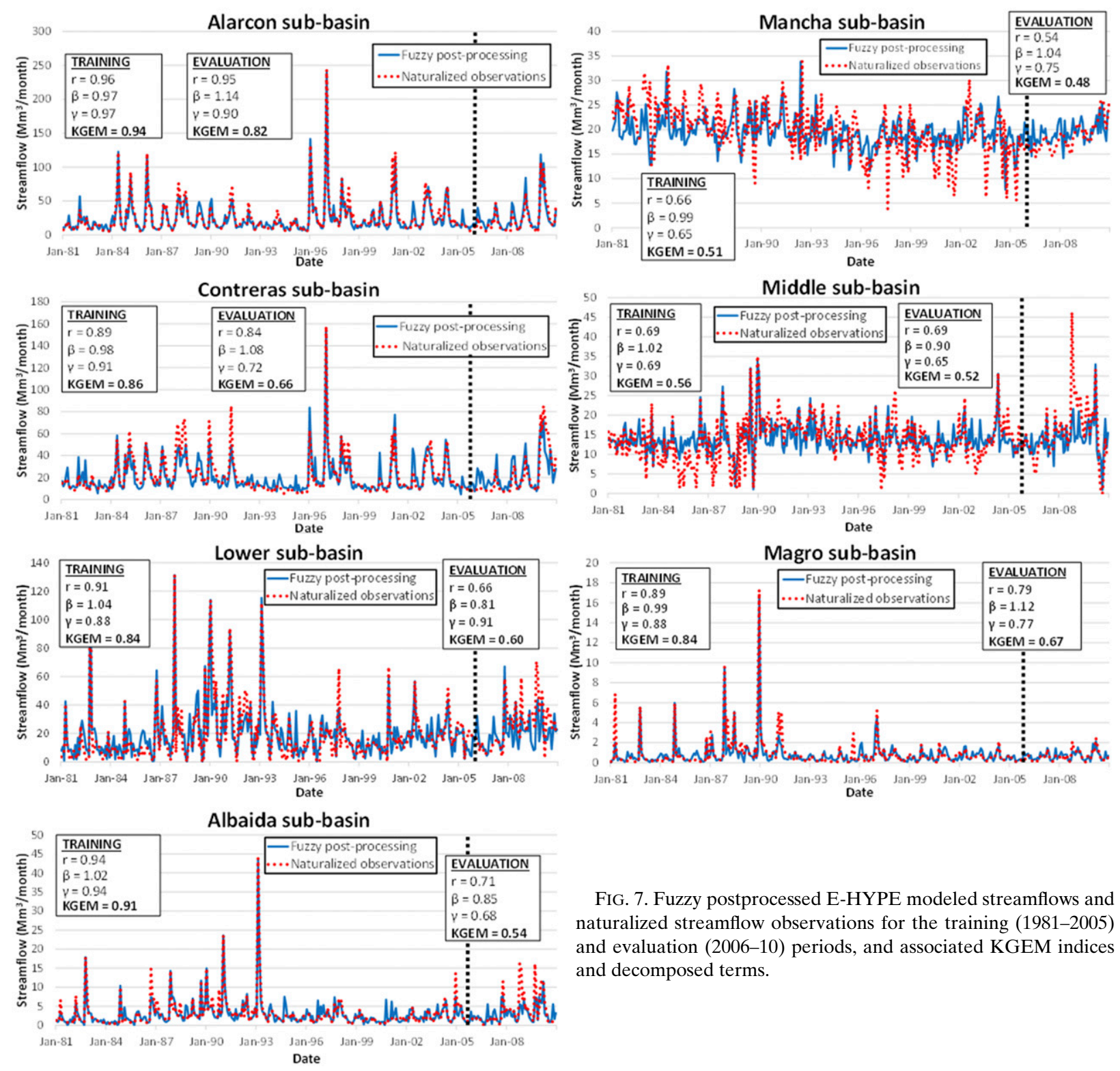

FIG. 7. Fuzzy postprocessed E-HYPE modeled streamflows and naturalized streamflow observations for the training (1981-2005) and evaluation (2006-10) periods, and associated KGEM indices and decomposed terms.

human impacts. It is therefore not straightforward to set up a reliable service for all possible locations. Here, the application of the pan-European E-HYPE model at the Jucar River basin is quite challenging due to 1 ) the presence of distinct regulation facilities (e.g., reservoirs) that are generally difficult to represent and predict (e.g., due to variable and complex operating rules), 2) the intensive groundwater use affecting streamaquifer interaction, 3) the generally poor E-HYPE model performance, and 4) the generally poor skill from the predictive system (ECMWF System 4) in the region.

Overall, the fuzzy postprocess has some negative impact on the forecasting skill, which can be significant depending on the season and subbasin, although it still delivers skillful forecasts for the Jucar River basin. This is due to two main factors. On one hand, it is caused by the role of the initial conditions, whose importance is partially lost after postprocessing. This is further justified given that the seasons with the highest loss in skill (winter and spring) are the ones in which the difference between meteorological and hydrological forecast skill is the highest. On the other hand, we observe a relationship between the correlation of modeled streamflows and naturalized observations, the performance of the fuzzy logic systems and the skill of postprocessed forecasts. However, there are subbasins whose skill improves after postprocessing (i.e., Contreras during summer and autumn), which may be due to including as postprocessing inputs catchments with higher skill than the one of the closest catchment (e.g., using Alarcon in the postprocessing of Contreras's forecasts).

The proposed fuzzy postprocessing method increased the potential of E-HYPE forecasts for the Jucar River basin. 


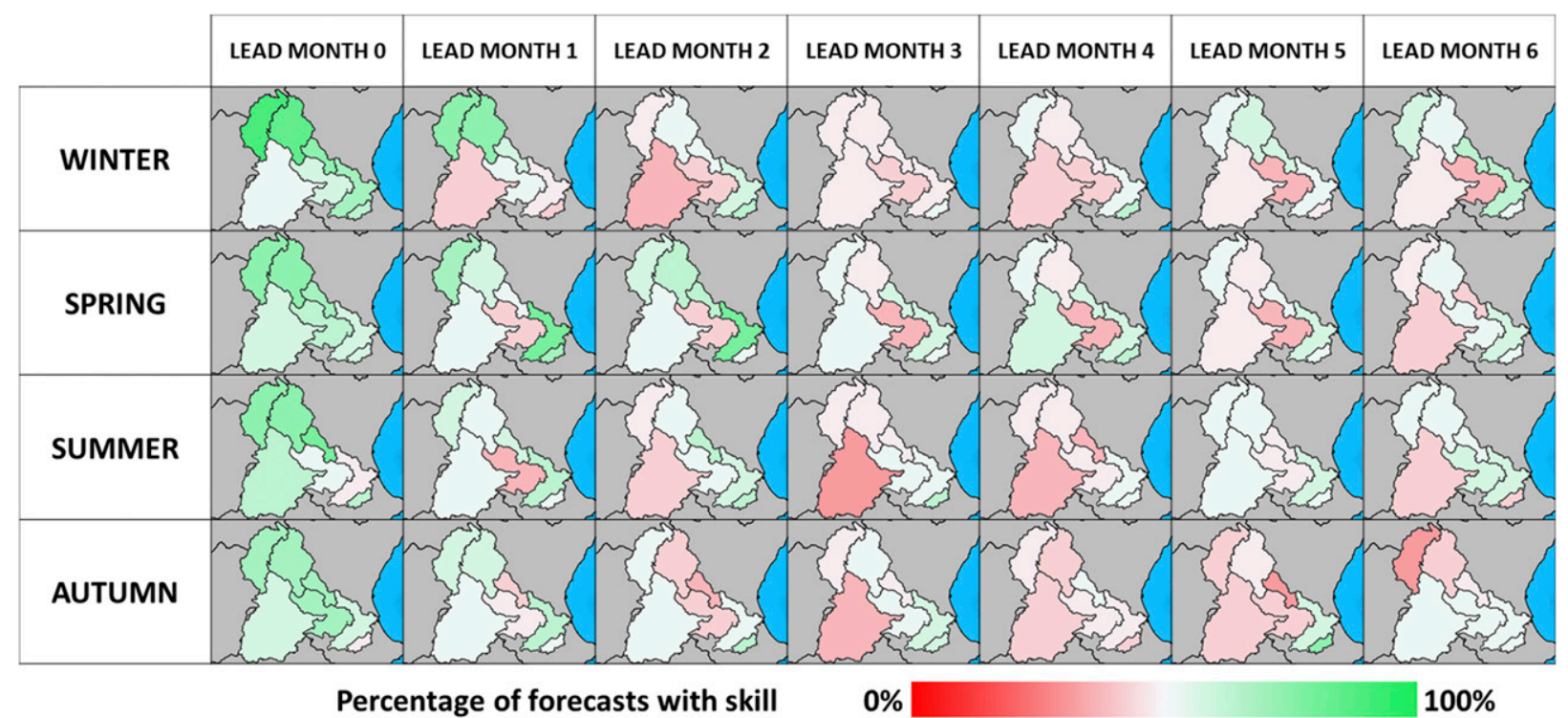

FIG. 8. Percentage of forecasts with skill of fuzzy postprocessed E-HYPE seasonal streamflow forecasts (positive CRPSS) using postprocessed modeled streamflows as reference. Percentages above $50 \%$ mean skillful forecasts (green tones) while percentages below $50 \%$ mean unskillful forecasts (red tones).

This justifies the usability of the proposed methodology and demonstrates a procedure to derive skillful seasonal streamflow forecasts from continental models at the regional scale. The performance of the E-HYPE model varies significantly over the river basin (good in the Alarcon subbasin and poor in parts of its middle and lower subbasins), which consequently results into different fuzzy postprocessing performance. The linkage found between the performance of fuzzy logic systems and the resulting forecasting skill indicates the conditions under which the proposed methodology can be successful. Furthermore, the added value obtained with the proposed methodology in such a challenging basin demonstrates its potential for the postprocessing of hydrological forecasts. Another suggestion is the possibility to include forecasts from neighboring basins with adequate skill in order to provide more skillful postprocessed forecasts. This highlights the potential of the methodology to generate

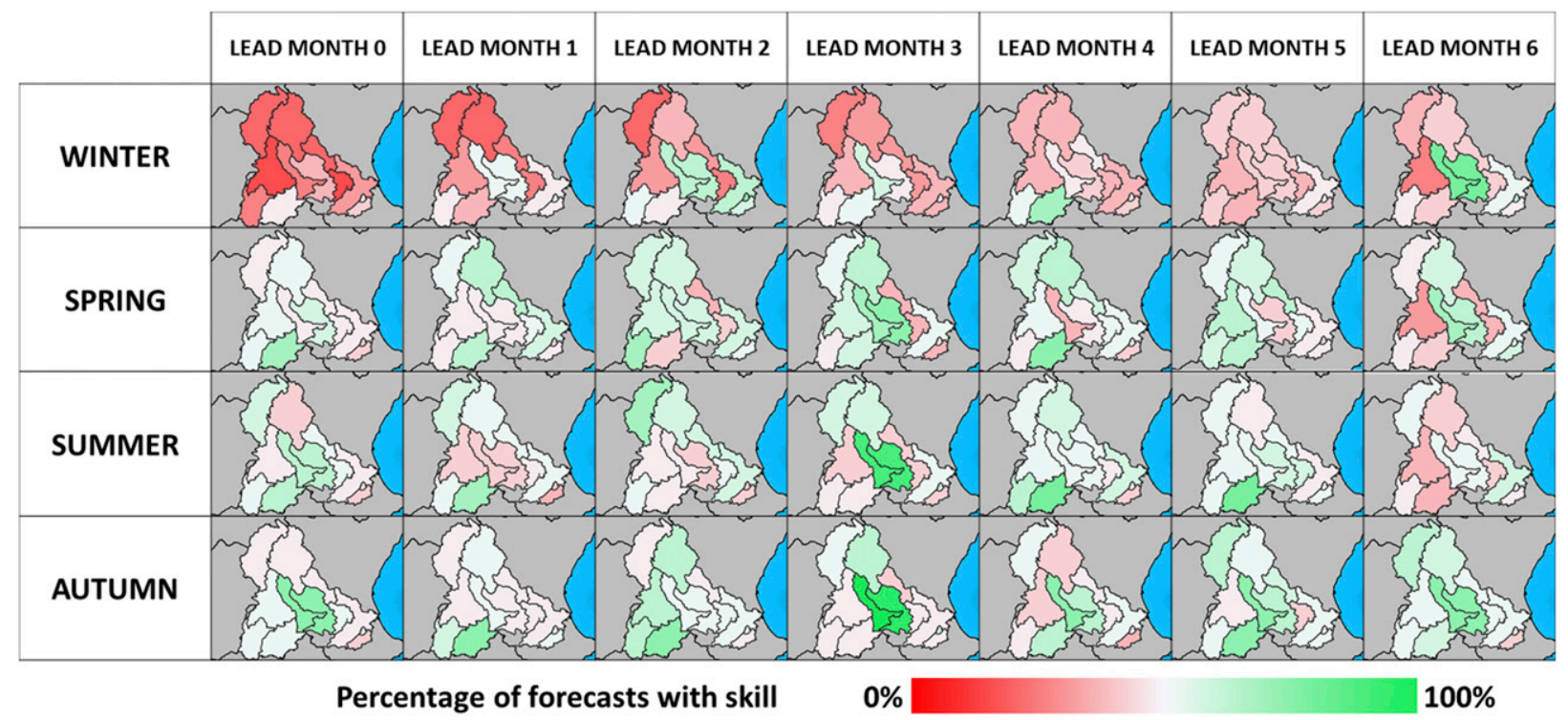

FIG. 9. Percentage of forecasts with skill of fuzzy postprocessed E-HYPE seasonal streamflow forecasts (positive CRPSS) using raw forecasts as reference. Percentages above $50 \%$ mean skillful forecasts (green tones) while percentages below $50 \%$ mean unskillful forecasts (red tones). 


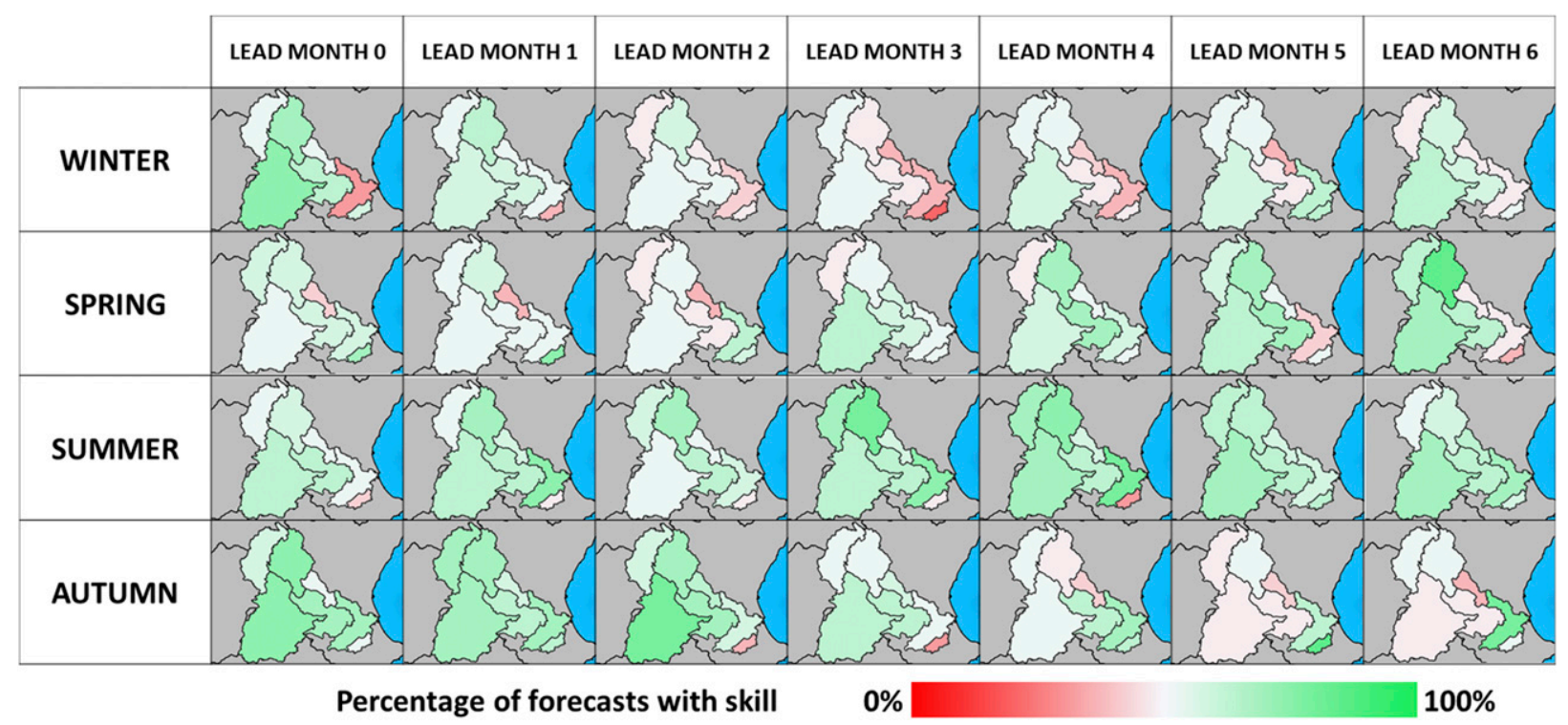

FIG. 10. Percentage of forecasts with skill of fuzzy postprocessed E-HYPE seasonal streamflow forecasts (positive CRPSS) using as reference quantile mapping postprocessed forecasts. Percentages above $50 \%$ mean skillful forecasts (green tones) while percentages below $50 \%$ mean unskillful forecasts (red tones).

skillful forecasts in basins with modeled streamflows but not forecasts, or when forecasts do not show skill, by including in their input set forecasts from neighboring basins that show skill. However, this approach would require historical streamflow observations in the target basin.

Moreover, forecasts can be provided as anomalies, percentiles of their cumulative probability distributions, or as standardized indices, i.e., the standardized runoff index (Crochemore et al. 2020; Shukla and Wood 2008). Although this alternative would be valid in most case studies, its application to the Jucar River basin is hindered by the null values shown by the cumulative probability distributions of raw E-HYPE streamflow forecasts $(11 \%-28 \%$ of null values depending on the catchment). This issue flattens the cumulative probability distribution, limiting the provision of accurate streamflow forecasts in case forecasts fall into its lower tail, which corresponds to a drought that affects the seasonal operation of the Jucar River.

Applying this methodology to additional river basins would require the collection of streamflow observations for the locations at which forecasts are desired; the acquisition of seasonal forecasts and modeled streamflows from the continental service in a preset of candidate input catchments for the hindcast period of the forecasting service; the choice of input catchments for each desired location comparing the observations with the modeled streamflows; the training and validation of postprocessing fuzzy logic systems mapping the input modeled streamflows to the observations for each location; and the assessment of skill of the postprocessed streamflow forecasts. It will require the existence of adequate streamflow observations for the desired locations and the finding of catchments from the continental service that share a relationship with them.

\section{b. Fuzzy postprocessing versus quantile mapping}

The prevalence of fuzzy logic over quantile mapping is due to the mapping provided by the method and its possibility to incorporate to the input set forecasts with adequate skill from the neighboring areas. While quantile mapping methods map forecasts using the probability distribution, fuzzy logic maps modeled streamflows and naturalized observations preserving the temporal dependence structure of the time series. However, this mapping can be challenged by strong deviations between E-HYPE modeled streamflows and naturalized observations. Nevertheless, there are some exceptions in the middle parts of the Jucar (Mancha and Middle subbasins) in which fuzzy postprocessing outperforms quantile mapping although fuzzy logic systems show low performance levels. This may be explained by the fact that the hydrological functioning of these subbasins (with a very strong groundwater component) also poses a distinct challenge to quantile mapping, which cannot correct systematic timing errors due to misrepresented processes.

Compared to quantile mapping, the proposed method neither depends on assumptions nor calculations of probability distributions. The postprocessed approach is not tailored to a particular forecasting service, since the fuzzy logic systems' building requires only modeled streamflows. Fuzzy logic can also accommodate more input catchments, if needed, which is not straightforward when using quantile mapping. Finally, the method requires careful input choice and analysis to take advantage of the possibilities offered by fuzzy logic.

\section{Summary and conclusions}

A methodology is proposed for postprocessing continental seasonal hydrological forecasts, tailoring the forecasts to the regional hydrological regime. This procedure relies on building 
fuzzy logic systems that map seasonal hydrological forecasts from a continental model to streamflow forecasts at target locations. Fuzzy logic systems are trained and evaluated using modeled hydrological streamflows obtained from a continental model and naturalized observations at target locations. Fuzzy postprocessed seasonal streamflow forecasts from the panEuropean E-HYPE model over the Jucar River basin (Spain) highlighted the improvements in skill over the commonly used quantile mapping approach. In particular, the following remarks are concluded:

- Streamflow forecasts from continental existing services (the pan-European E-HYPE model) in the Jucar River basin can deliver skillful forecasts up to lead month 3 depending on season and location. However, raw forecasts from these services may not be used directly due to significant differences between the model setup and the Jucar River basin features, requiring the use of postprocessing methods.

- Fuzzy logic has proven to be a suitable method to postprocess forecasts from E-HYPE, although the process implies in general some loss of skill. This loss ranges between a slight decrease in the headwaters of the Jucar (even showing an increase in skill in specific areas) and distinct losses in the rest of the river basin, although still delivering skillful forecasts. The skill of postprocessed forecasts is linked to the performance shown by the fuzzy logic systems built for the process.

- Fuzzy-based postprocessed forecasts show in general higher skill than quantile mapping based postprocessed forecasts. Nevertheless, the difference in skill between both methods is not very large. Overall, we highlight the potential of fuzzy logic as a suitable postprocessing method, and also stress the necessity to analyze additional postprocessing methods to address the full potential of continental forecasting services.

Acknowledgments. This study was partially funded by the EU Horizon 2020 programme under the IMPREX research and innovation project (grant agreement no. 641.811), by the European Research Area for Climate Services programme (ER4CS) under the INNOVA project (Grant Agreement 690462), by the ADAPTAMED project (RTI2018-101483-B-I00) from the Ministerio de Ciencia, Innovación Universidades (MICINN) of Spain, and by the postdoctoral program of Universitat Politècnica de València (PAID 10-18). Funding was also received from the EU Horizon 2020 project S2S4E (Sub-seasonal to Seasonal forecasting for the Energy sector) under Grant Agreement 776787. This study was also partially funded by the EU Horizon 2020 project CLARA under the Grant Agreement 730482.

\section{REFERENCES}

Abbaspour, K. C., E. Rouholahnejad, S. Vaghefi, R. Srinivasan, H. Yang, and B. Kløve, 2015: A continental-scale hydrology and water quality model for Europe: Calibration and uncertainty of a high-resolution large-scale SWAT model. J. Hydrol., 524, 733-752, https://doi.org/10.1016/j.jhydrol.2015.03.027.

Andersson, J. C. M., I. Pechlivanidis, D. Gustafsson, C. Donnelly, and B. Arheimer, 2015: Key factors for improving large-scale hydrological model performance. Eur. Water, 49, 77-88.
Arnal, L., M.-H. Ramos, E. Coughlan de Perez, H. L. Cloke, E. Stephens, F. Wetterhall, S. J. van Andel, and F. Pappenberger, 2016: Willingness-to-pay for a probabilistic flood forecast: A risk-based decision-making game. Hydrol. Earth Syst. Sci., 20, 3109-3128, https://doi.org/10.5194/hess-20-3109-2016.

— , A. W. Wood, E. Stephens, H. L. Cloke, and F. Pappenberger, 2017: An efficient approach for estimating streamflow forecast skill elasticity. J. Hydrometeor., 18, 1715-1729, https://doi.org/ 10.1175/JHM-D-16-0259.1.

- , H. L. Cloke, E. Stephens, F. Wetterhall, C. Prudhomme, J. Neumann, B. Krzeminski, and F. Pappenberger, 2018: Skilful seasonal forecasts of streamflow over Europe? Hydrol. Earth Syst. Sci., 22, 2057-2072, https://doi.org/10.5194/hess-222057-2018.

Beck, H. E., A. I. J. M. van Dijk, A. de Roo, D. G. Miralles, T. R. McVicar, J. Schellekens, and L. A. Bruijnzeel, 2016: Global-scale regionalization of hydrologic model parameters. Water Resour. Res., 52, 3599-3622, https://doi.org/10.1002/2015WR018247.

Berg, P., C. Donnelly, and D. Gustafsson, 2018: Near-real-time adjusted reanalysis forcing data for hydrology. Hydrol. Earth Syst. Sci., 22, 989-1000, https://doi.org/10.5194/hess-22-9892018.

Brown, C., and P. Rogers, 2006: Effect of forecast-based pricing on irrigated agriculture: A simulation. J. Water Resour. Plann. Manage., 132, 403-413, https://doi.org/10.1061/(ASCE)07339496(2006)132:6(403).

CEDEX, 2016: Anuario de aforos 2015-2016 (in Spanish). Centro de Estudios Hidrográficos del Centro de Experimentación de Obras Públicas, Ministerio para la Transición Ecológica y el Reto Demográfico, https://ceh.cedex.es/anuarioaforos/ default.asp.

CHJ, 2015: Plan Hidrológico de la Demarcación Hidrográfica del Júcar Memoria: Ciclo de Planificación Hidrológica 2015-2021 (in Spanish). Tech. Rep., Confederación Hidrográfica del Júcar, Ministerio de Agricultura, Alimentación y Medio Ambiente, 896 pp.

Contreras, E., J. Herrero, L. Crochemore, I. Pechlivanidis, C. Photiadou, C. Aguilar, and M. J. Polo, 2020: Advances in the definition of needs and specifications for a climate service tool aimed at small hydropower plants' operation and management. Energies, 13, 1827, https://doi.org/10.3390/ en13071827.

Crochemore, L., M.-H. Ramos, F. Pappenberger, S. J. van Andel, and A. W. Wood, 2016: An experiment on risk-based decisionmaking in water management using monthly probabilistic forecasts. Bull. Amer. Meteor. Soc., 97, 541-551, https://doi.org/ 10.1175/BAMS-D-14-00270.1.

,-- , and I. G. Pechlivanidis, 2020: Can continental models convey useful seasonal hydrologic information at the catchment scale? Water Resour. Res., 56, e2019WR025700, https:// doi.org/10.1029/2019WR025700.

Dobson, B., T. Wagener, and F. Pianosi, 2019: An argument-driven classification and comparison of reservoir operation optimization methods. Adv. Water Resour., 128, 74-86, https://doi.org/ 10.1016/j.advwatres.2019.04.012.

Donnelly, C., J. C. M. Andersson, and B. Arheimer, 2016: Using flow signatures and catchment similarities to evaluate the E-HYPE multi-basin model across Europe. Hydrol. Sci. J., 61, 255-273, https://doi.org/10.1080/02626667.2015.1027710.

Ficchì, A., L. Raso, D. Dorchies, F. Pianosi, P. Malaterre, P. Van Overloop, and M. Jay-Allemand, 2016: Optimal operation of the multireservoir system in the Seine river basin using deterministic and ensemble forecasts. J. Water 
Resour. Plann. Manage., 142, 05015005, https://doi.org/10.1061/ (ASCE)WR.1943-5452.0000571.

Foster, K., C. Bertacchi Uvo, and J. Olsson, 2018: The development and evaluation of a hydrological seasonal forecast system prototype for predicting spring flood volumes in Swedish rivers. Hydrol. Earth Syst. Sci., 22, 2953-2970, https://doi.org/ 10.5194/hess-22-2953-2018.

Giuliani, M., L. Crochemore, I. Pechlivanidis, and A. Castelletti, 2020: From skill to value: Isolating the influence of end-user behaviour on seasonal forecast assessment. Hydrol. Earth Syst. Sci. Discuss., https://doi.org/10.5194/hess-2019-659.

Guo, G., S. Liu, W. Yipeng, J. Li, R. Zhou, and X. Zhu, 2018: Shortterm water demand forecast based on deep learning method. J. Water Resour. Plann. Manage., 144, 04018076, https:// doi.org/10.1061/(ASCE)WR.1943-5452.0000992.

Hersbach, H., 2000: Decomposition of the continuous ranked probability score for ensemble prediction systems. Wea. Forecast., 15, 559-570, https://doi.org/10.1175/1520-0434(2000)015<0559: DOTCRP $>2.0 . C O ; 2$.

Hundecha, Y., B. Arheimer, C. Donnelly, and I. Pechlivanidis, 2016: A regional parameter estimation scheme for a panEuropean multi-basin model. J. Hydrol. Reg. Stud., 6, 90-111, https://doi.org/10.1016/j.ejrh.2016.04.002.

Johnson, S. J., and Coauthors, 2019: SEAS5: The new ECMWF seasonal forecast system. Geosci. Model Dev., 12, 1087-1117, https://doi.org/10.5194/gmd-12-1087-2019.

Kauffeldt, A., S. Halldin, A. Rodhe, C.-Y. Xu, and I. K. Westerberg, 2013: Disinformative data in large-scale hydrological modelling. Hydrol. Earth Syst. Sci., 17, 2845-2857, https://doi.org/10.5194/ hess-17-2845-2013.

Kling, H., M. Fuchs, and M. Paulin, 2012: Runoff conditions in the upper Danube basin under an ensemble of climate change scenarios. J. Hydrol., 424-425, 264-277, https://doi.org/10.1016/ j.jhydrol.2012.01.011.

Lavers, D. A., and Coauthors, 2020: A vision for hydrological prediction. Atmosphere, 11, 237, https://doi.org/10.3390/ atmos11030237.

Li, W., Q. Duan, C. Miao, A. Ye, W. Gong, and Z. Di, 2017: A review on statistical postprocessing methods for hydrometeorological ensemble forecasting. Wiley Interdiscip. Rev.: Water, 4, e1246, https://doi.org/10.1002/wat2.1246.

Li, Y., M. Giuliani, and A. Castelletti, 2017: A coupled humannatural system to assess the operational value of weather and climate services for agriculture. Hydrol. Earth Syst. Sci., 21, 4693-4709, https://doi.org/10.5194/hess-21-4693-2017.

Lindström, G., C. Pers, J. Rosberg, J. Strömqvist, and B. Arheimer, 2010: Development and testing of the HYPE (Hydrological Predictions for the Environment) water quality model for different spatial scales. Hydrol. Res., 41, 295-319, https:// doi.org/10.2166/nh.2010.007.

Macian-Sorribes, H., and M. Pulido-Velazquez, 2017: Integrating historical operating decisions and expert criteria into a DSS for the management of a multireservoir system. J. Water Resour. Plann. Manage., 143, 04016069, https://doi.org/10.1061/(ASCE) WR.1943-5452.0000712.

MacLachlan, C., and Coauthors, 2015: Global Seasonal forecast system version 5 (GloSea5): A high-resolution seasonal forecast system. Quart. J. Roy. Meteor. Soc., 141, 1072-1084, https://doi.org/10.1002/qj.2396.

Maraun, D., and Coauthors, 2010: Precipitation downscaling under climate change: Recent developments to bridge the gap between dynamical models and the end user. Rev. Geophys., 48 , RG3003, https://doi.org/10.1029/2009RG000314.
Matheson, J. E., and R. L. Winkler, 1976: Scoring rules for continuous probability distributions. Manage. Sci., 22, 1087-1096, https://doi.org/10.1287/mnsc.22.10.1087.

Meißner, D., B. Klein, and M. Ionita, 2017: Development of a monthly to seasonal forecast framework tailored to inland waterway transport in central Europe. Hydrol. Earth Syst. Sci., 21, 6401-6423, https://doi.org/10.5194/hess-21-6401-2017.

Nazemi, A., and H. S. Wheater, 2015: On inclusion of water resource management in Earth system models - Part 1: Problem definition and representation of water demand. Hydrol. Earth Syst. Sci., 19, 33-61, https://doi.org/10.5194/hess-19-33-2015.

Neumann, J., L. Arnal, R. Emerton, H. Griffith, S. Hyslop, S. Theofanidi, and H. L. Cloke, 2018a: Can seasonal hydrological forecasts inform local decisions and actions? A decisionmaking activity. Geosci. Commun., 1, 35-57, https://doi.org/ 10.5194/gc-1-35-2018.

,$- \ldots$, L. Magnusson, and H. Cloke, 2018b: The 2013/14 thames basin floods: Do improved meteorological forecasts lead to more skillful hydrological forecasts at seasonal time scales? J. Hydrometeor., 19, 1059-1075, https://doi.org/10.1175/ JHM-D-17-0182.1.

Pechlivanidis, I. G., and B. Arheimer, 2015: Large-scale hydrological modelling by using modified PUB recommendations: The India-HYPE case. Hydrol. Earth Syst. Sci., 19, 4559-4579, https://doi.org/10.5194/hess-19-4559-2015.

- L. L. Crochemore, J. Rosberg, and T. Bosshard, 2020: What are the key drivers controlling the quality of seasonal streamflow forecasts? Water Resour. Res., 56, e2019WR026987, https:// doi.org/10.1029/2019WR026987.

Pianosi, F., and R. Soncini-Sessa, 2009: Real-time management of a multipurpose water reservoir with a heteroscedastic inflow model. Water Resour. Res., 45, W10430, https://doi.org/10.1029/ 2008WR007335.

Pina, J., A. Tilmant, and P. Côté, 2017: Optimizing multireservoir system operating policies using exogenous hydrologic variables. Water Resour. Res., 53, 9845-9859, https://doi.org/10.1002/ 2017WR021701.

Ramos, M.-H., J. Bartholmes, and J. Thielen-del Pozo, 2007: Development of decision support products based on ensemble forecasts in the European flood alert system. Atmos. Sci. Lett., 8, 113-119, https://doi.org/10.1002/asl.161.

Rani, D., and M. M. Moreira, 2010: Simulation-optimization modeling: A survey and potential application in reservoir systems operation. Water Resour. Manage., 24, 1107-1138, https://doi.org/10.1007/s11269-009-9488-0.

Raso, L., and O. Malaterre, 2017: Combining short-term and longterm reservoir operation using infinite horizon model predictive control. J. Irrig. Drain. Eng., 143, B4016002, https://doi.org/ 10.1061/(ASCE)IR.1943-4774.0001063.

Russell, S. O., and P. F. Campbell, 1996: Reservoir operating rules with fuzzy programming. J. Water Resour. Plann. Manage., 122, 165-170, https://doi.org/10.1061/(ASCE)0733-9496(1996) 122:3(165).

Samaniego, L., R. Kumar, and S. Attinger, 2010: Multiscale parameter regionalization of a grid-based hydrologic model at the mesoscale. Water Resour. Res., 46, W05523, https://doi.org/ 10.1029/2008WR007327.

Sen, Z., 2010: Fuzzy Logic and Hydrological Modeling. CRC Press, 348 pp.

Shrestha, B. P., L. Duckstein, and E. Z. Stakhiv, 1996: Fuzzy rulebased modeling of reservoir operation. J. Water Resour. Plann. Manage., 122, 262-269, https://doi.org/10.1061/(ASCE)07339496(1996)122:4(262). 
Shukla, S., and A. W. Wood, 2008: Use of a standardized runoff index for characterizing hydrologic drought. Geophys. Res. Lett., 35, L02405, https://doi.org/10.1029/2007GL032487.

—, J. Sheffield, E. F. Wood, and D. P. Lettenmaier, 2013: On the sources of global land surface hydrologic predictability. Hydrol. Earth Syst. Sci., 17, 2781-2796, https://doi.org/10.5194/ hess-17-2781-2013.

Sreekanth, J., B. Datta, and P. K. Mohapatra, 2012: Optimal shortterm reservoir operation with integrated long-term goals. Water Resour. Manage., 26, 2833-2850, https://doi.org/10.1007/ s11269-012-0051-z.

Teutschbein, C., F. Wetterhall, and J. Seibert, 2011: Evaluation of different downscaling techniques for hydrological climatechange impact studies at the catchment scale. Climate Dyn., 37, 2087-2105, https://doi.org/10.1007/s00382-010-0979-8.

Turan, M. E., and M. A. Yurdusev, 2016: Fuzzy conceptual hydrological model for water flow prediction. Water Resour. Manage., 30, 653-667, https://doi.org/10.1007/s11269-015-1183-8.

Wanders, N., S. Thober, R. Kumar, M. Pan, J. Sheffield, L. Samaniego, and E. F. Wood, 2019: Development and evaluation of a pan-European multimodel seasonal hydrological forecasting system. J. Hydrometeor., 20, 99-115, https://doi.org/ 10.1175/JHM-D-18-0040.1.
Wetterhall, F., H. C. Winsemius, E. Dutra, M. Werner, and E. Pappenberger, 2015: Seasonal predictions of agrometeorological drought indicators for the Limpopo basin. Hydrol. Earth Syst. Sci., 19, 2577-2586, https://doi.org/ 10.5194/hess-19-2577-2015.

Wood, A. W., and D. P. Lettenmaier, 2008: An ensemble approach for attribution of hydrologic prediction uncertainty. Geophys. Res. Lett., 35, L14401, https://doi.org/10.1029/ 2008 GL034648.

—, T. Hopson, A. Newman, L. Brekke, J. Arnold, and M. Clark, 2016: Quantifying streamflow forecast skill elasticity to initial condition and climate prediction skill. J. Hydrometeor., 17, 651-668, https://doi.org/10.1175/JHM-D-14-0213.1.

Wu, X., C. Cheng, Y. Zeng, and J. Lund, 2016: Centralized versus distributed cooperative operating rules for multiple cascaded hydropower reservoirs. J. Water Resour. Plann. Manage., 142, 05016008, https://doi.org/10.1061/(ASCE) WR.1943-5452.0000685.

Yang, W., J. Andréasson, L. Phil Graham, J. Olsson, J. Rosberg, and F. Wetterhall, 2010: Distribution-based scaling to improve usability of regional climate model projections for hydrological climate change impacts studies. Hydrol. Res., 41, 211-229, https://doi.org/10.2166/nh.2010.004. 